Avicenna Journal of Nursing and Midwifery Care - ISSN 2676-5748

\title{
Effective Factors on Caring Role of Parents of Children With Cerebral Palsy
}

\author{
Nasrin Alaee ${ }^{1}$, Farahnaz Mohammadi-Shahboulaghi2 ${ }^{*}$, Hamid Reza Khankeh ${ }^{3}$, \\ Sima MohammadKhan Kermanshahi ${ }^{4}$
}

1. Department of Nursing, Faculty of Nursing and Midwifery, Shahed University, Tehran, Iran

2. Assistant Professor, Social Determinant of Health Research Center, University of Social Welfare and Rehabilitation Sciences, Tehran, Iran

3. Associate Professor, Department of Nursing, University of Social Welfare and Rehabilitation Sciences, Tehran, Iran

4. Associate Professor, Department of Nursing, Faculty of Medicine, Tarbiat Modares University, Tehran, Iran

\section{Article Info \\ Received: 2018/02/08 \\ Accepted: 2018/06/25 \\ Published Online: 2019/03/22}

DOI: 10.30699 /ajnmc.27.1.55

Original Article

Use your device to scan and read the article online

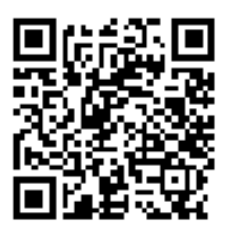

Corresponding Information

\section{Abstract}

Introduction: Parents of children with cerebral palsy are exposed to the complications of the child's care; they need kinds of support to reduce problems of care for the child. Therefore, the current study was done in order to discover the factors that influence role of caring parents while taking care of the cerebral palsy child.

Methods: This study is part of a qualitative study that was done in 2011-2013. Sampling was done based on goal-oriented and continued to saturate data. Thus 33 participants including parents and family members of children with cerebral palsy that had been referred to Rehabilitation Centers in Tehran city and rehabilitation experts participated in this study. Data was collected through semi-structured interviews with each participant and analyzed through content analysis and continuous comparison of data.

Results: The results of data analysis showed the concept of parental capital with two categories: parents' personal ability (subcategories: mental and physical ability in care, the ability to communicate with others, belief in the spiritual value of the child) and parental situational resources (subcategories: the socio-economic status of the family, the availability of helping relatives, cooperation and partnership in the family).

Conclusion: Parental capital as a supporting factor has an effectiveness on the sense of parents' dominance on the situation of taking care of child; so 'it is important to pay attention to the parents' capital (internal and external) for educating and home care planning of affected child and family.

Keywords: Parents, Children, Caring, Cerebral Palsy, Illness

Farahnaz Mohammadi-Shahboulaghi, Assistant Professor, Social Determinant of Health Research Center, 


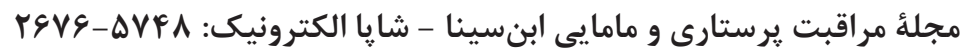

مقاله يثزوهشى

عوامل مؤثر بر نقش مراقبتى والدين كودكان مبتلا به فلج مغزى

نسرين علائى'، فر حناز محمدى شاهبلاغى ז"، حميدرضا خانكه"، سيما محمدخان كرمانشاهى"

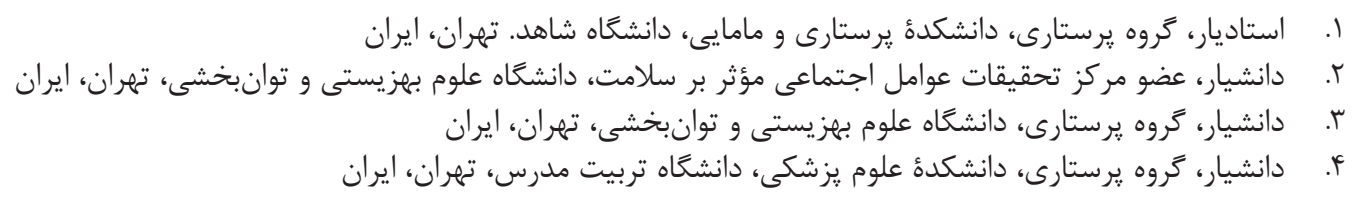

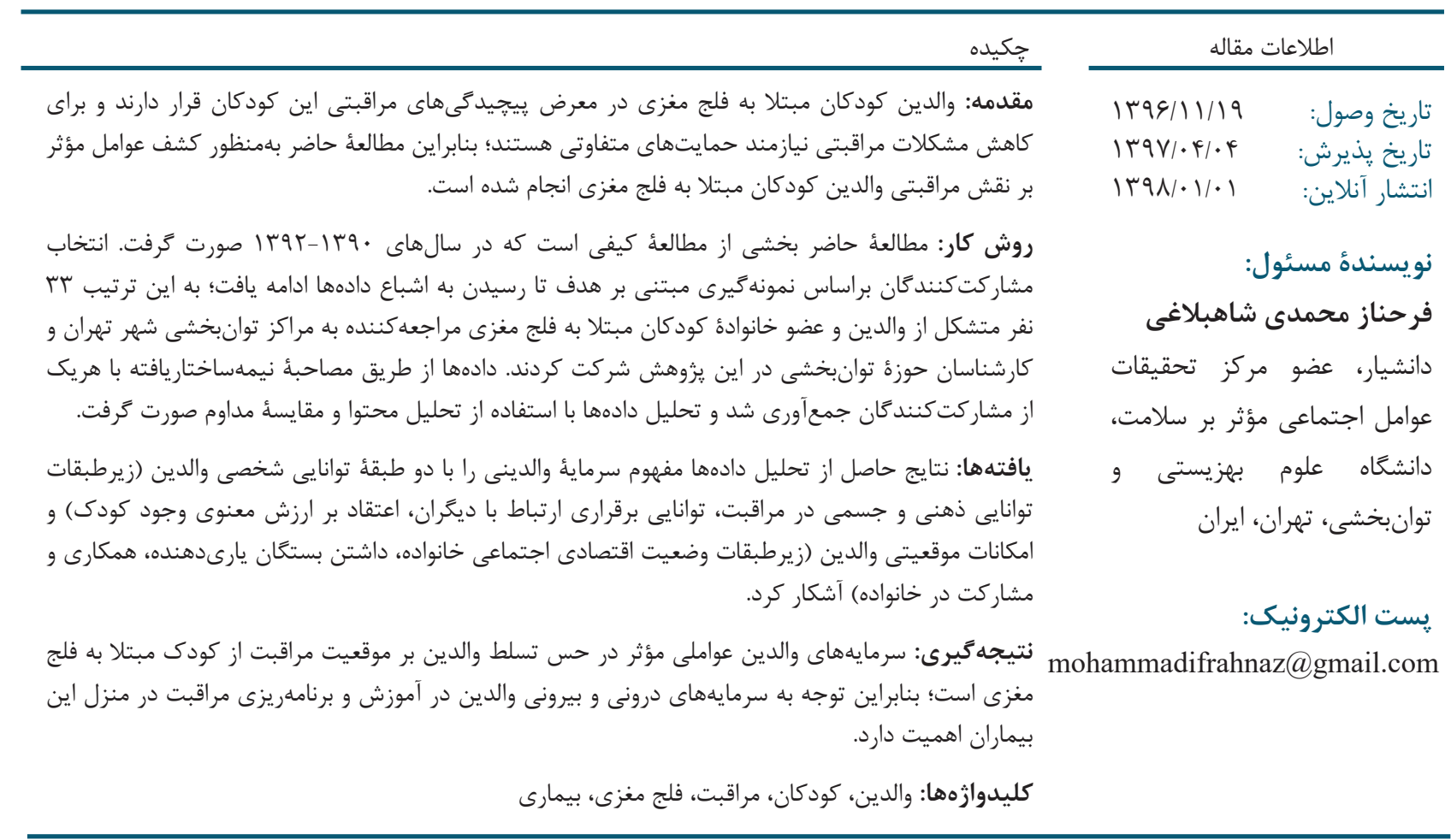

مقدمه

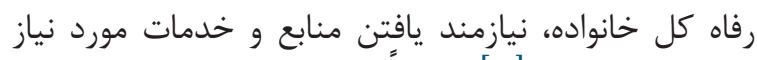

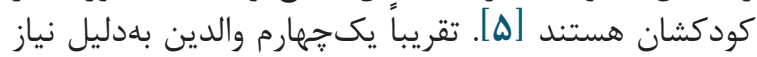

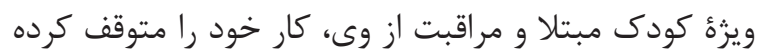

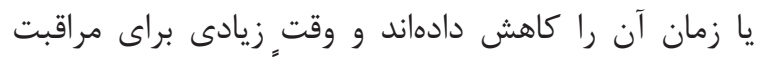

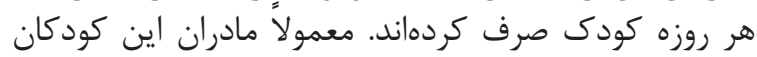

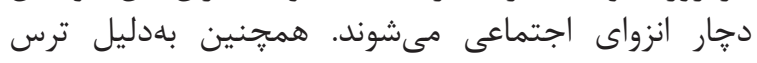

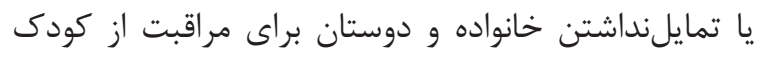

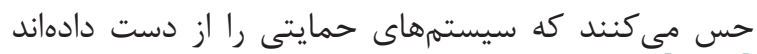

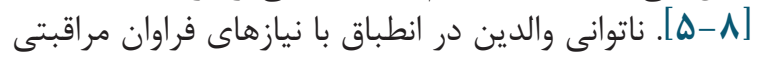

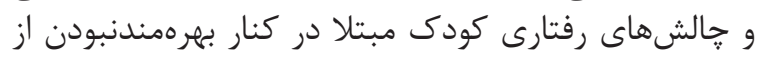

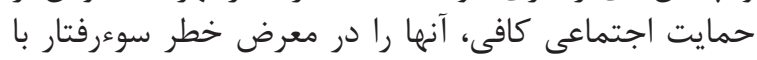

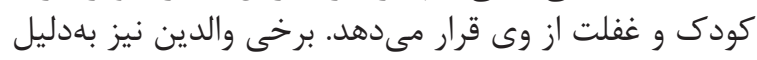

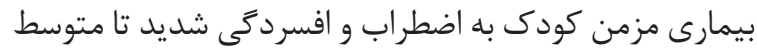

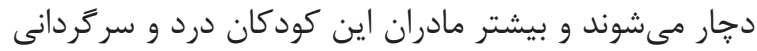

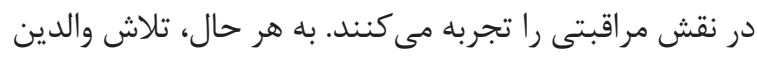

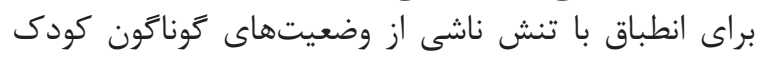

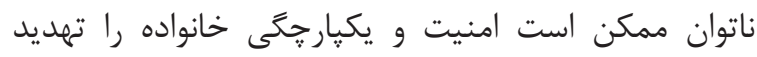

با وجود يِيشرفتهاى اخير در مراقبتهاى زايته زايمانى،

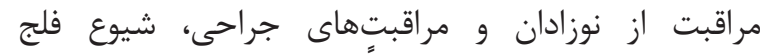

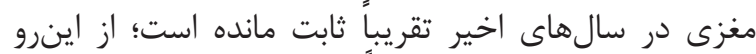

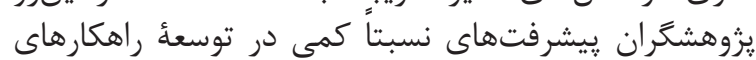

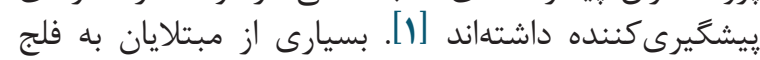

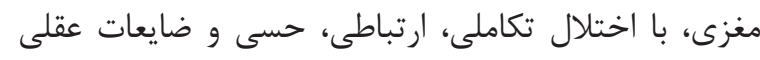

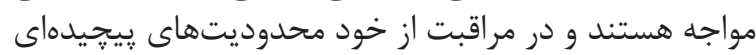

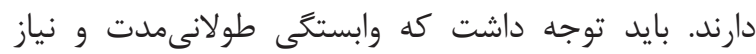

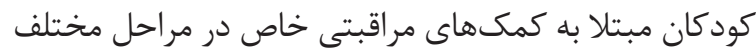

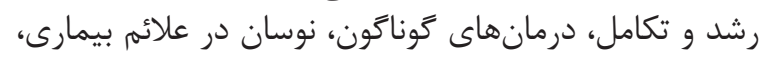

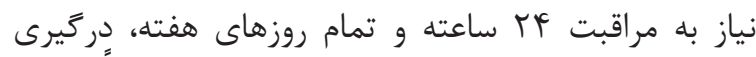

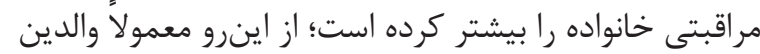

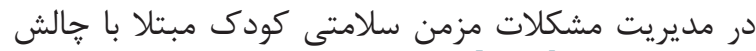

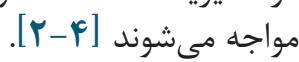

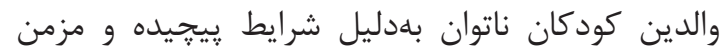

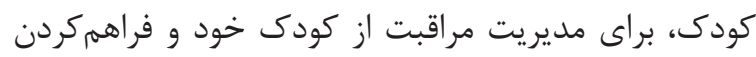


در منزل صورت كرفت. مصاحبهها ضبط شد و در در مواردى

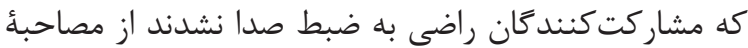

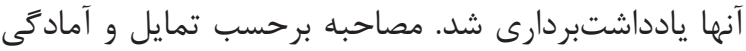

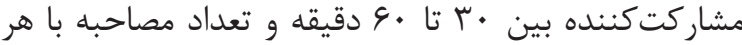

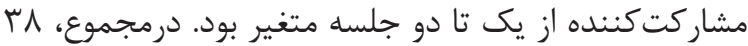

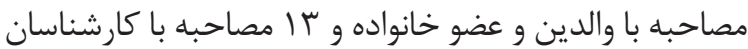

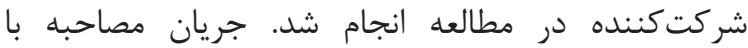

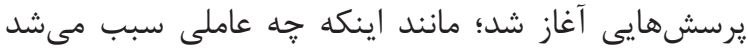

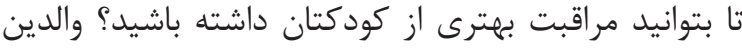

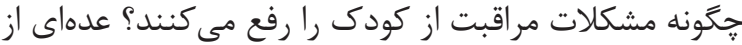

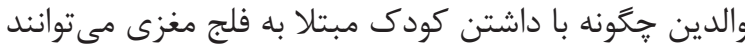

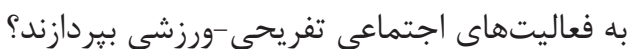

سيس مصاحبه با تكيه بر برسشهايى كه در در تعامل

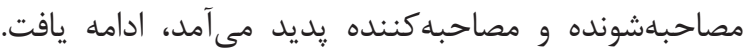

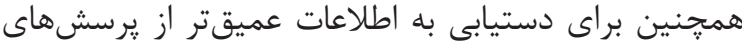

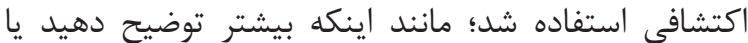

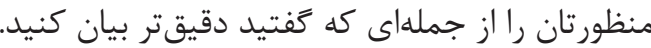

در اين يزوهش بهمنظور تحليل دادهها، از مراحل تحليل

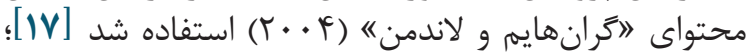

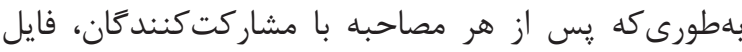

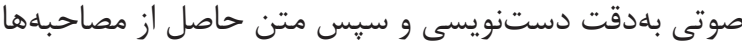

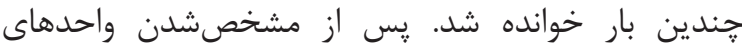

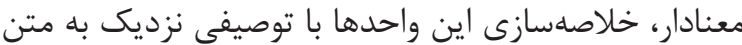

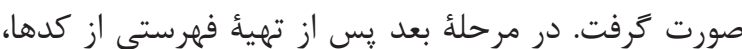

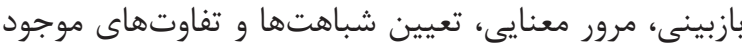

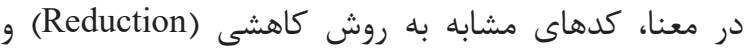

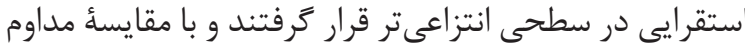
زيرطبقات و طبقات قابل دقبول حاصل شدر

براى اطمينان از صحت يافتهها (Trustworthiness)

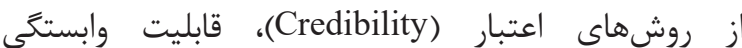
(Dependability)

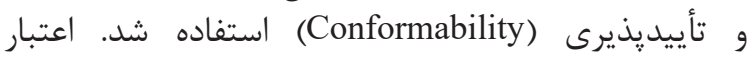

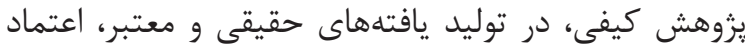

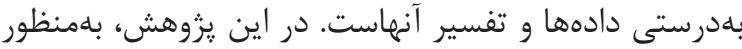

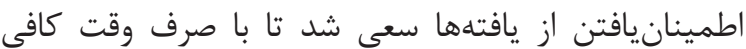

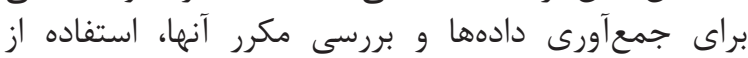

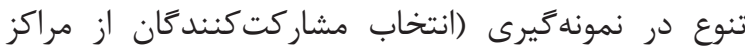

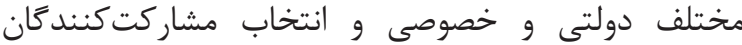

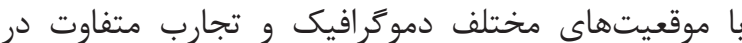

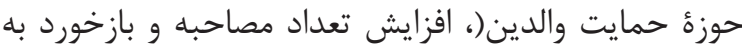

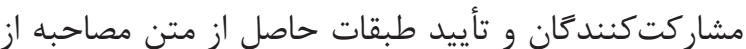

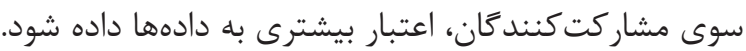

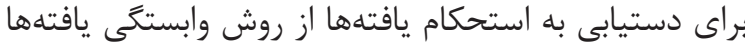

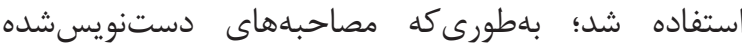

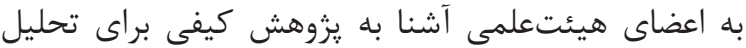

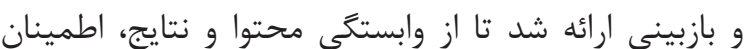

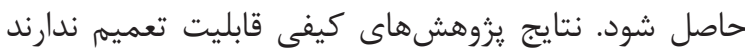

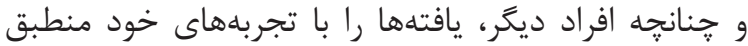

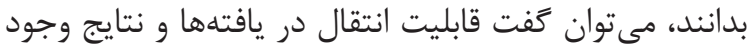

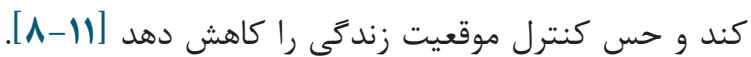

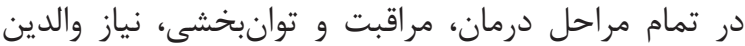

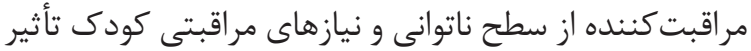

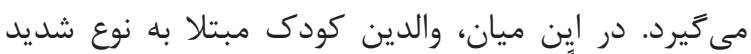

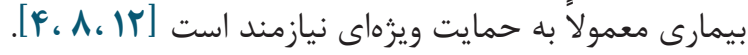

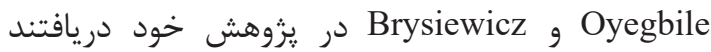

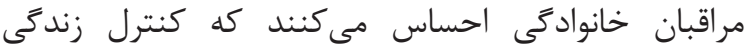

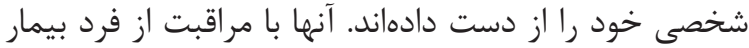

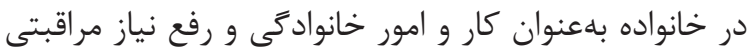

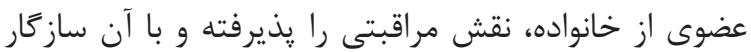

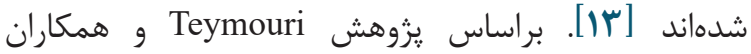

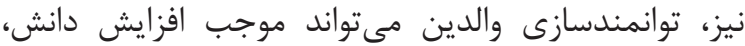

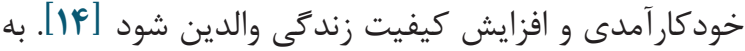

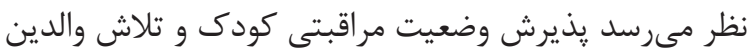

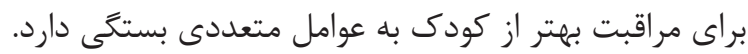

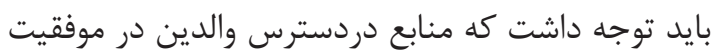

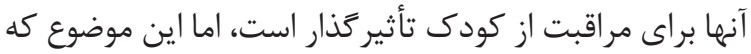

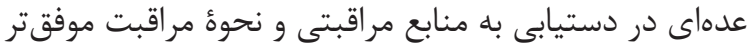

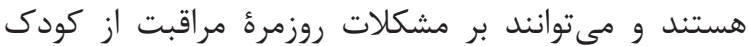

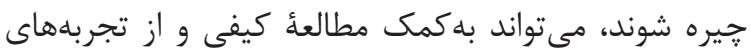

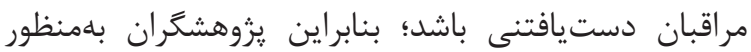

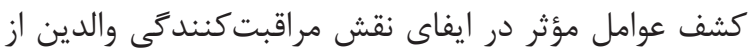
كودى مبتلا به فلج مغزى به مطالعأ فعلى ير ثرداختهاند.

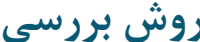

مطالعئ حاضر بخشى از مطالعهُ كيفى است كه در در سال

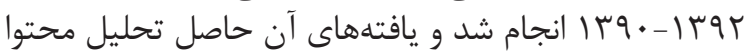

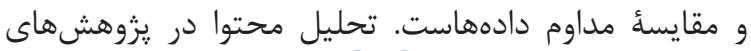

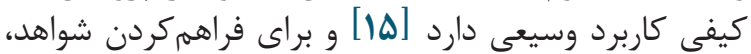

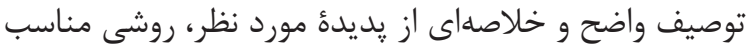

محسوب مى اضعود [19].

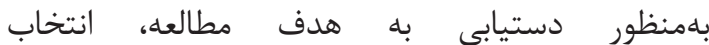

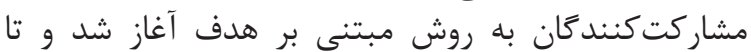

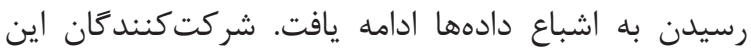

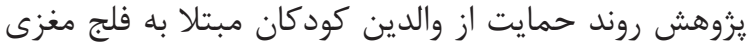

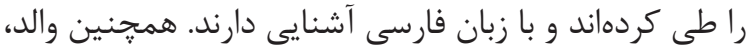

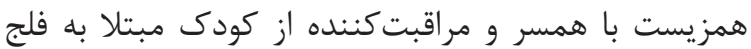

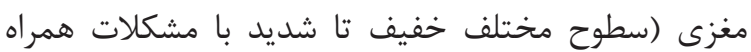

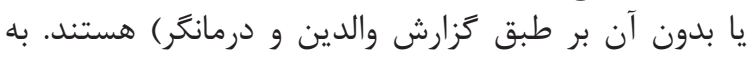

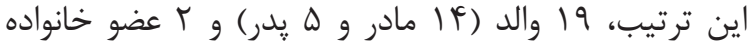

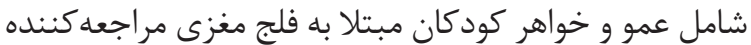

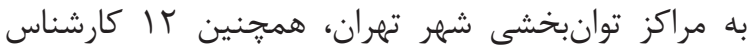

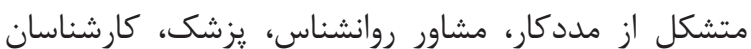

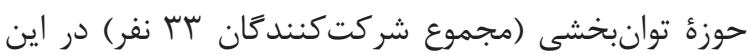
ئزوهش مشاركت داشتند. بلمنظور جمعآورى دادهها، از مصاحبئ نيمهساختاريافته

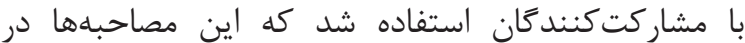

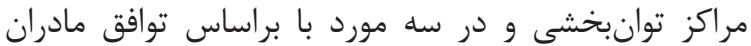




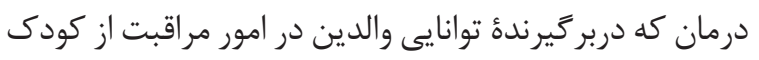

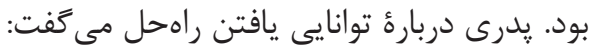

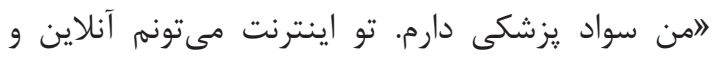

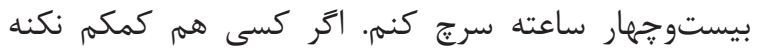

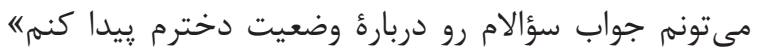

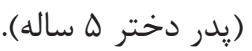

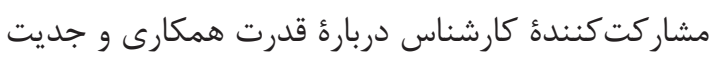

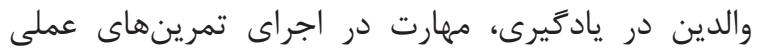

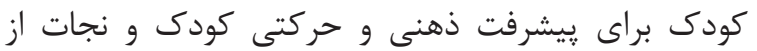

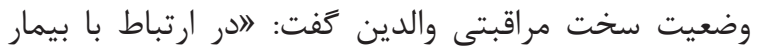

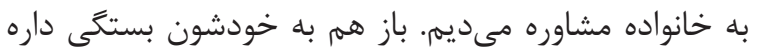

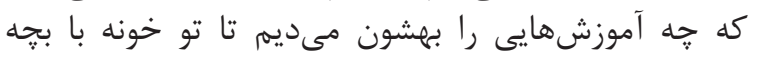

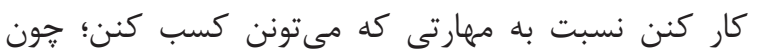

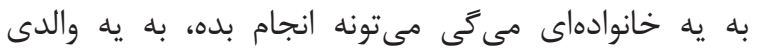

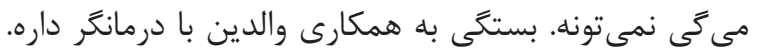

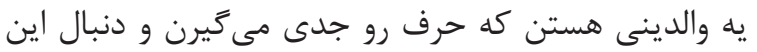

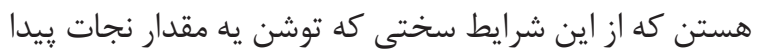
كنن" (كاردرمان با 1 سال سابقه).

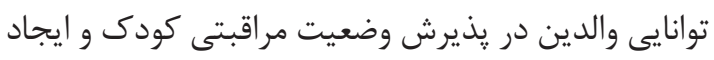

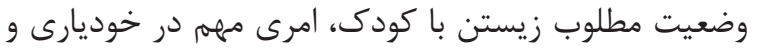
كمك به كودى مبتلاست. يكى از مشاركت كنيند

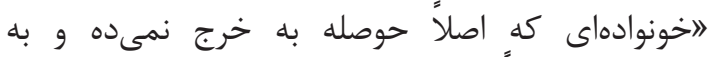

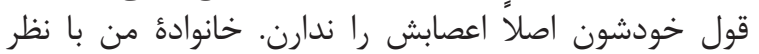

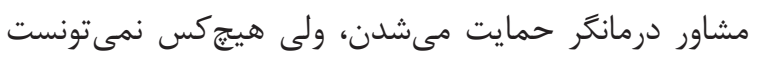

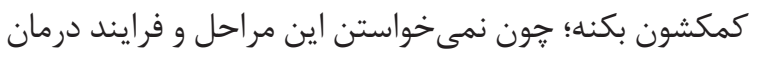

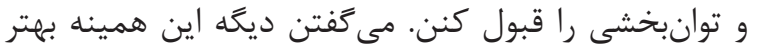

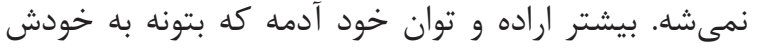

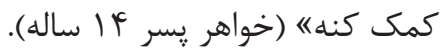

يذيرش وضعيت ناتوانى كودى و مراقبت از وى و قراردادن إدن

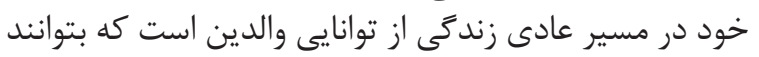

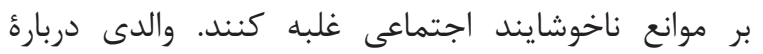

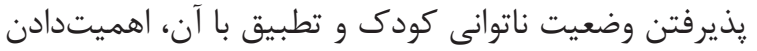

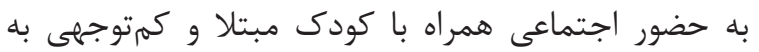

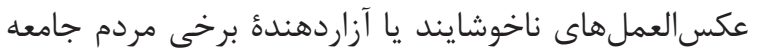

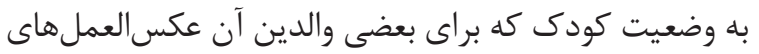

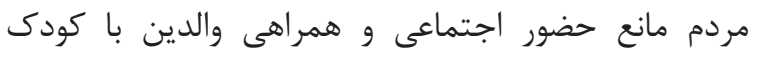

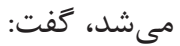

"امن بجه را همهجا مىبرم يارك، سينما. اينطور نيستم

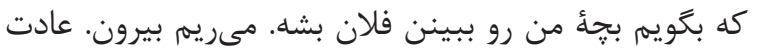

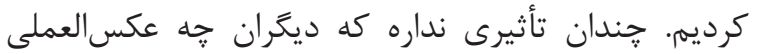

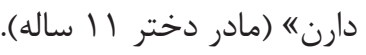

\section{r. اعتقاد بر ارزش معنوى وجود كودى مبتلا}

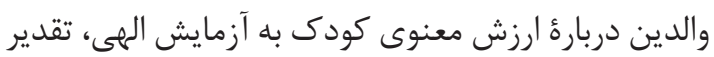

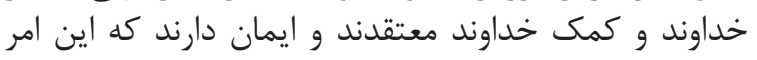

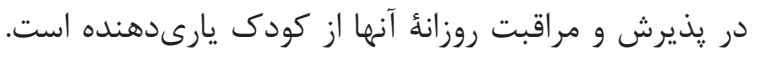

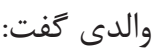

دارد [11]] در اين مطالعه نيز يزوهشكر قابليت انتقاليذيرى

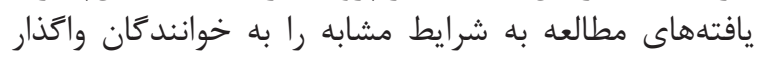

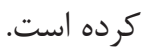

بامنظور رعايت ملاحظات اخلاقى، با كسب تأييديه كميتهٔ

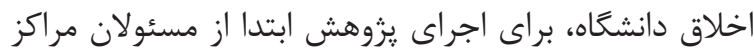

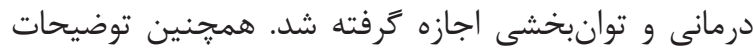

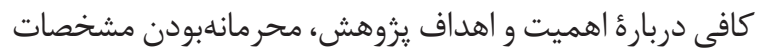

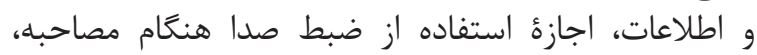

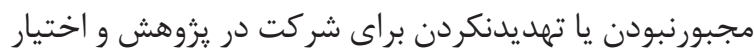

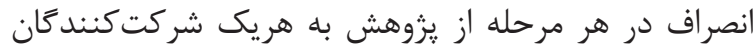

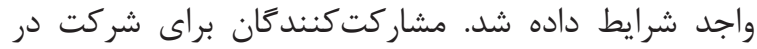

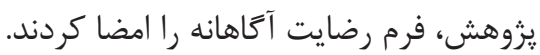

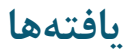

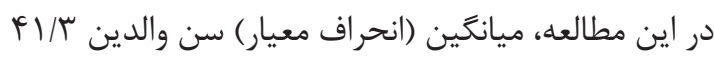

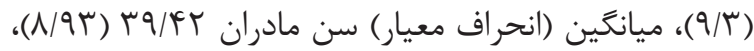

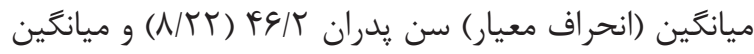

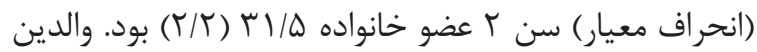

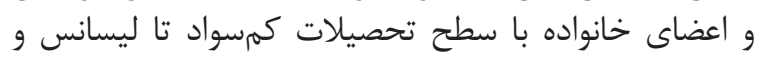

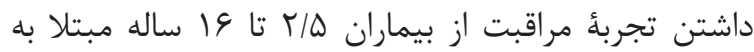

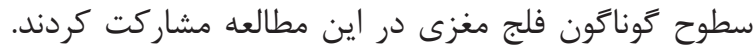

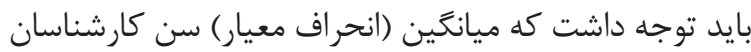

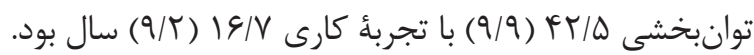
تحليل يافتهاى تجربأه مشاركت كنندكان، • آب كد اوليه،

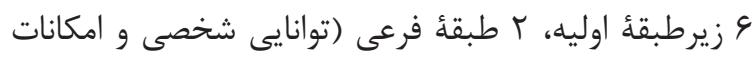

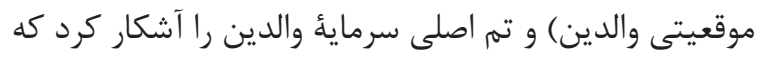
شرح آنها در جدول الدين آمده است سترمابة

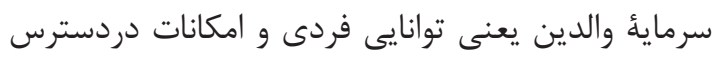

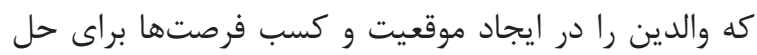

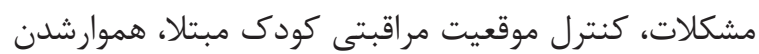

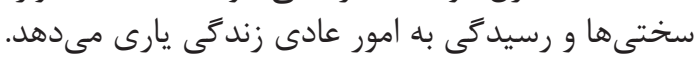

\section{توانايى شخصى والدين}

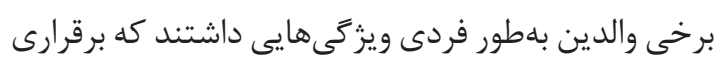

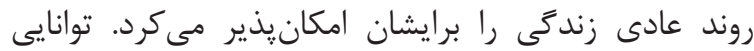

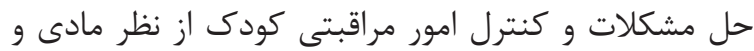

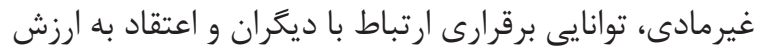

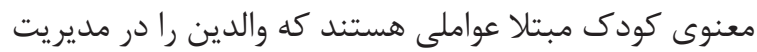

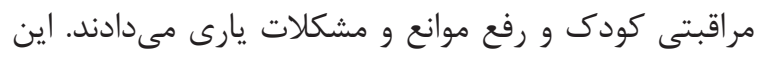

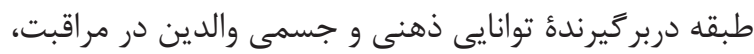

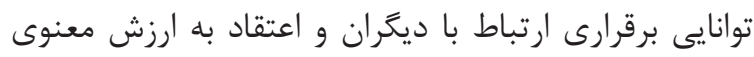

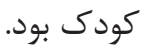

\section{ا. توانايى ذهنى و جسمى والدين در مراقبت}

توانايى در امور مراقبتى يعنى داشتن مجموعئ توانايى

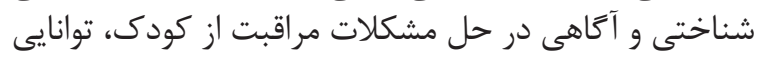

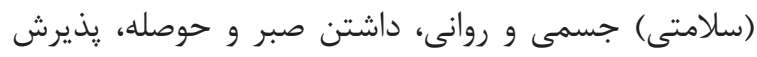

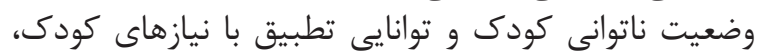

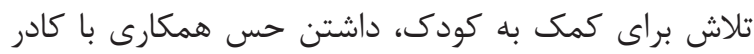


توان مالى كفت:

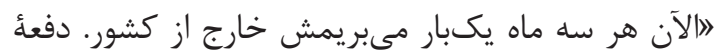

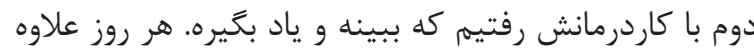

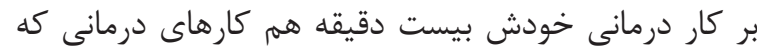

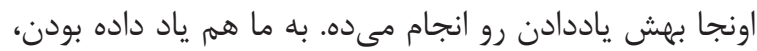

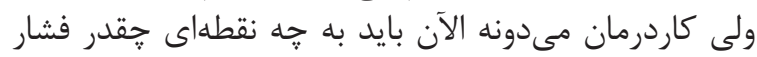

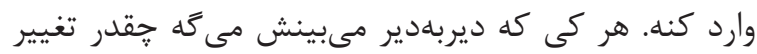

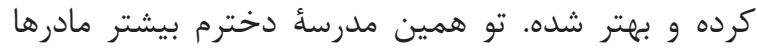

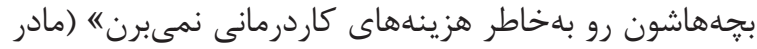

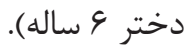

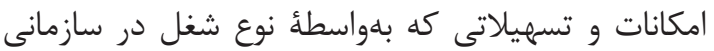

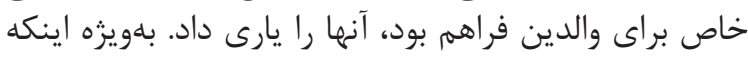

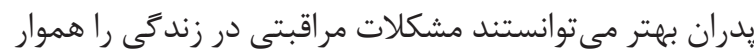
كنند. مشار كت كنندهاى مى تكفت:

الشهرستان امكانات كاردرمانى اينجا رو نداره. به علاوه

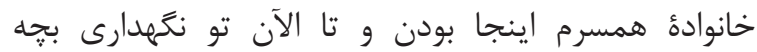

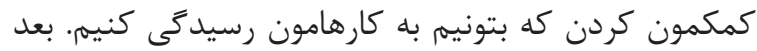

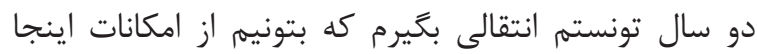

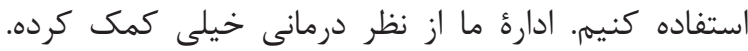

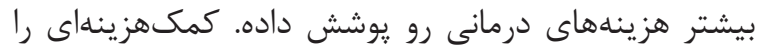

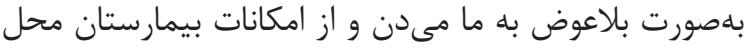

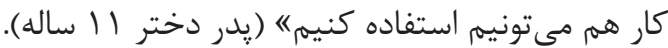

\section{r. آ وجود بستخان يارىدهنده}

كاهى والدين در وضعيتى قرار داشتند كه زمينه و فرصت

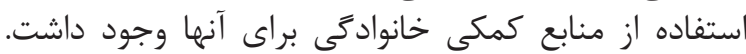

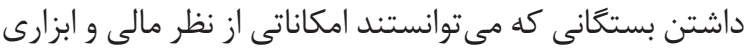

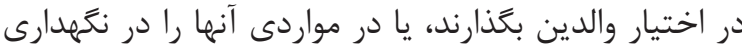

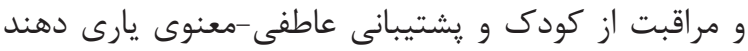

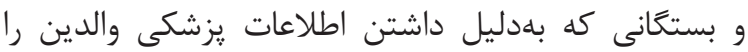

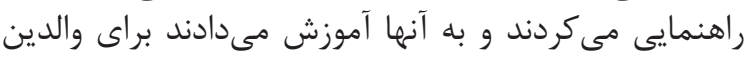

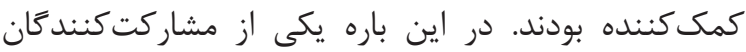

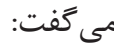

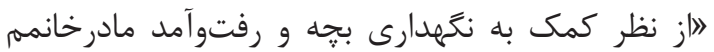

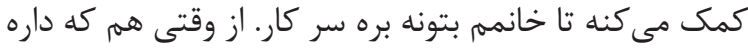

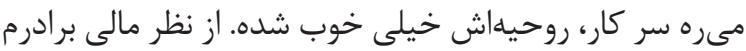

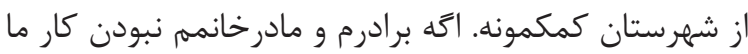

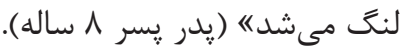
يدر ديخرى دربارئ توجه و لزوم يشتيبانى معنوى از سوى

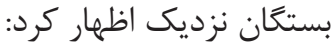

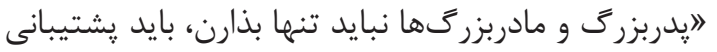

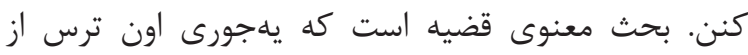

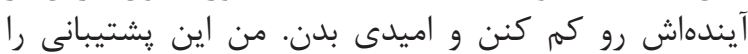

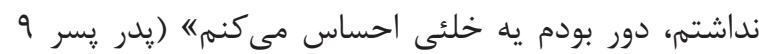

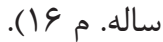

\section{r. وجود همكارى و مشاركت در خانواده}

داشتن روابط مناسب ميان والدين براى همكارى، مشاركت
اشوهرم خيلى مؤمنه و وجود اين بجه رو رواد تقدير خدا مىدونه《 (مادر دختر

كاهى اعتقاد به وجود معنوى و ارزشمند كودى مبد مبتلا

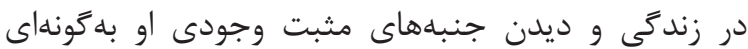

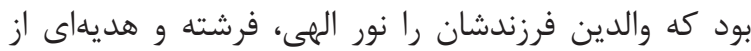

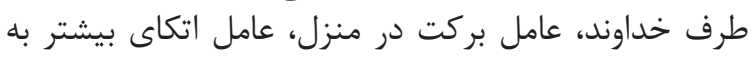

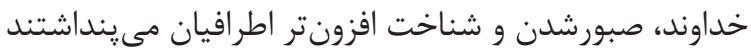

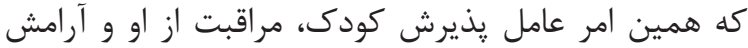

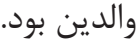

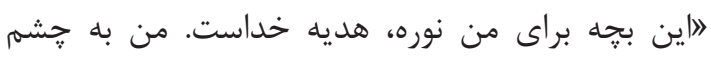

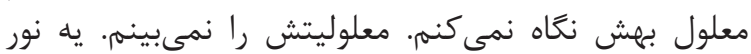

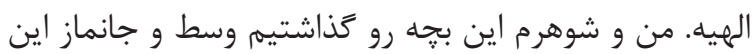

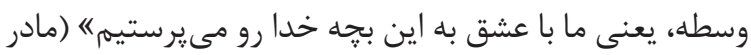

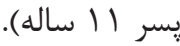

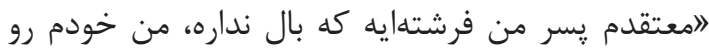

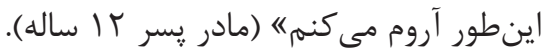

\section{r. توانايى برقرارى ارتباط با ديگران}

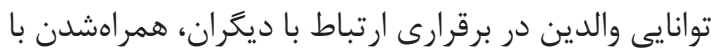

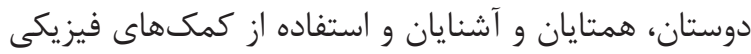

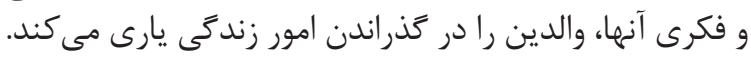

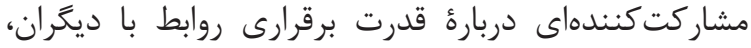

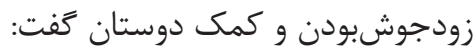
المن آدمى هستم كه با همه مى جوشم. دوستان زيادى

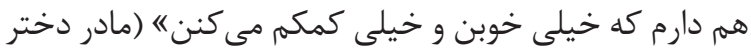

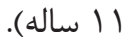

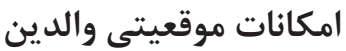

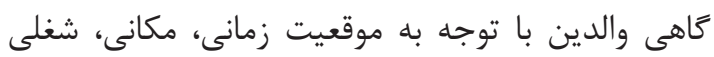

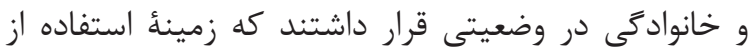

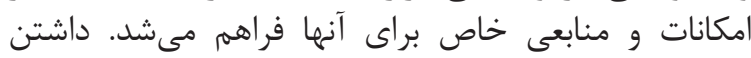

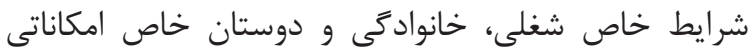

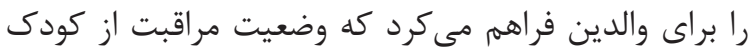

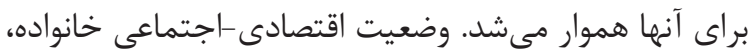

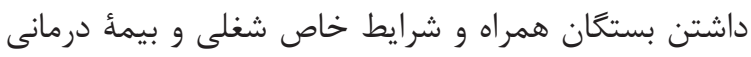
در اين طبقه قرار دارند. - ماند

\section{ا. وضعيت اقتصادى -اجتماعى خانواده}

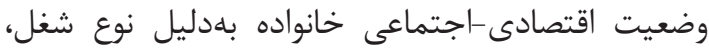

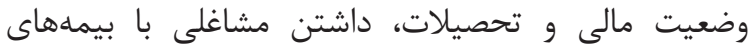

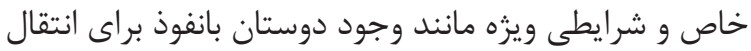

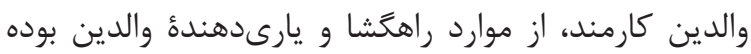

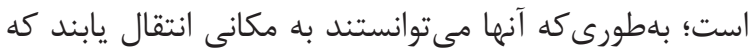

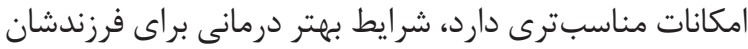

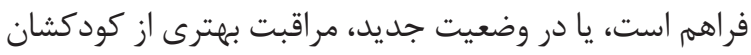

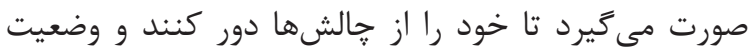

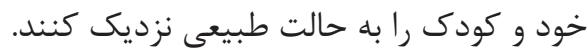
مشاركت كنندهاى از روند درمانى كودى مبتلا با توجه به 
دارم و فكر نمى كنهم كه اين فقط منمم كه بايد غصأ دخترم را بخورم" (مادر دختر 9 ساله).

يكى از كارشناسان درباره حس همكارى ميان اعضاى

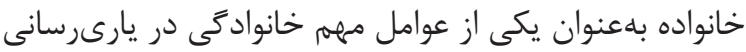

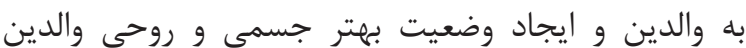
مراقبت كننده از كودى كفت

الدر خانوادههايى كه اعضاى اون در روند توانبخشى مانى

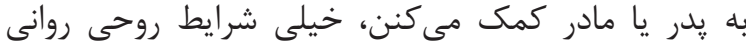

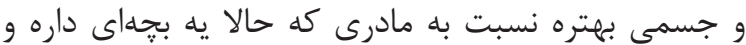

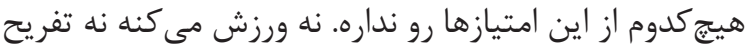

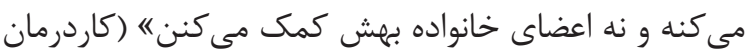
با مال مابقه).
و كمكرسانى فكرى و عملى به يكديخر در مراقبت از كودى إنى

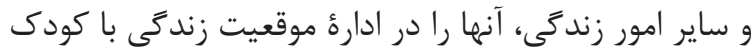

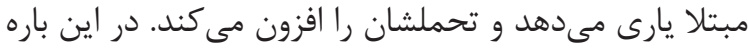
مشاركت كنند مان بيان كردند

الحالا ما يه زن و شوهر با همديگه مىتونيم همكارى

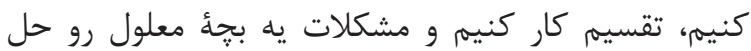
كنيه" (يدر دختر 1 (الهنه ساله).

همدلى و حس مشترك ميان والدين در يذيرش كودى

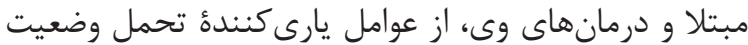

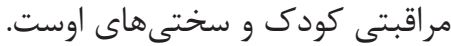

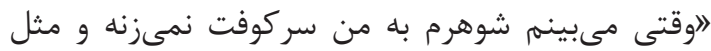

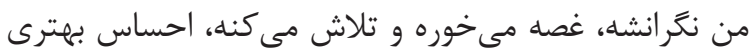

جدول ا. طبقات عوامل مؤثر بر نقش مراقبتى والدين كودكان مبتلا به فلج مغزى

زيرطبقات اوليه

توانايى ذهنى و جسمى در مراقبت

اعتقاد بر ارزش معنوى وجود كودى مبتلا

توانايى در برقرارى ارتباط با ديخران

وضعيت اقتصادى-اجتماعى

بستكان يارىدهنده

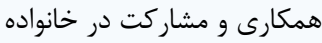

والدينى كه از منابع درونىشان آتاهترند، مطالب مورد نياز

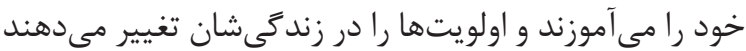

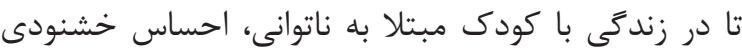
كنند [וا].

Guillamón شخصى مانند خود كار آمدى والدين، بر سلامت روان روان و كيفيت

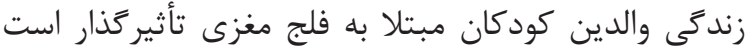

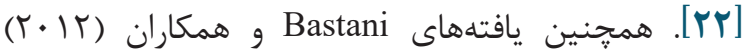

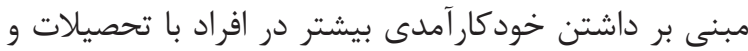

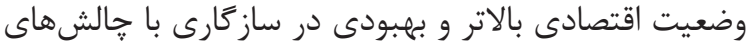

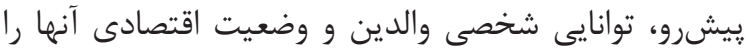

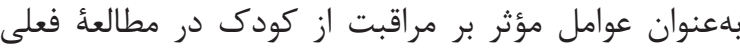

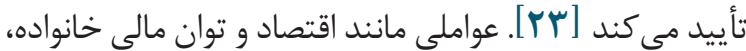
تحصيلات، وضعيت ناتوانى كودى در توجه بـ به رانئ راهبردهاى

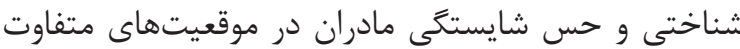

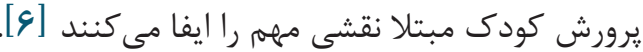

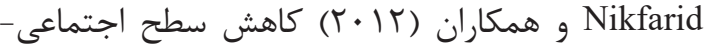
اقتصادى را عامل شكست مادران كودكان مبتلا به به بيمارى

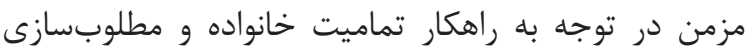

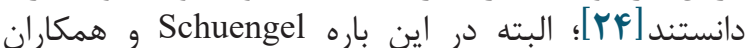

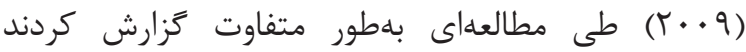

توانيى شخصى والدين

\section{طبقة اصلى}

" والدين

امكانات موقعيتى والدين

\section{بحث}

با توجه به يزوهش حاضر، توانايىهاى جسمى و ذهنى

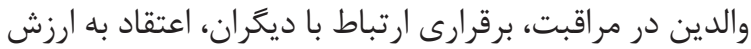

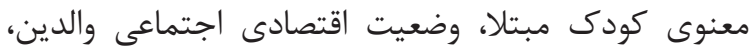

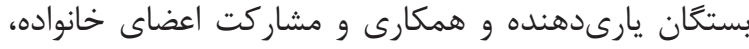

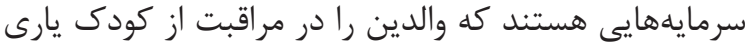
مى دهند.

سرمايه منبعى كلى است كه افراد از آن استفاده

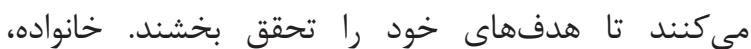

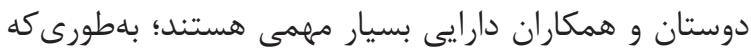

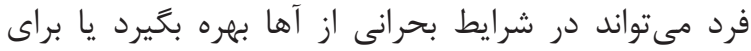

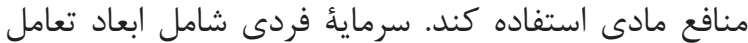

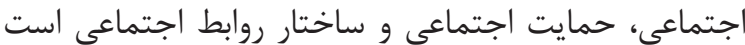
Mohammady.[19]

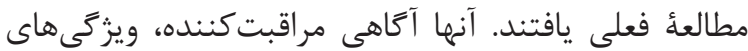

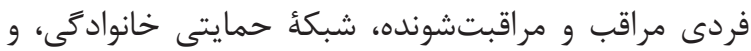

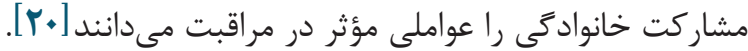

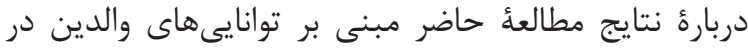

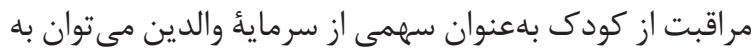

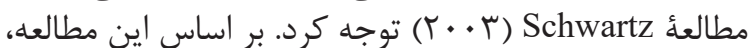


باورهاى دينى و معنوى معى معائوى مرانستند با وجود مشكلات

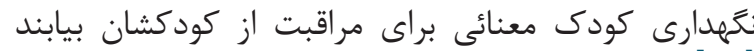

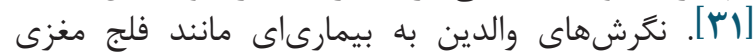

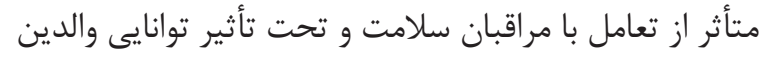

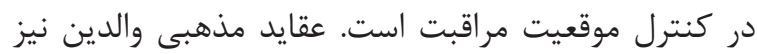

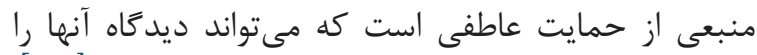

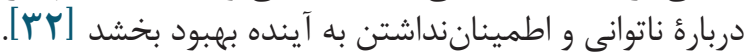

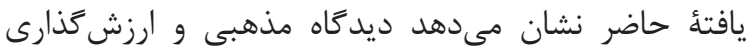

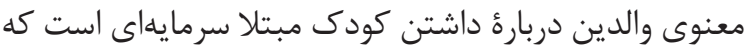

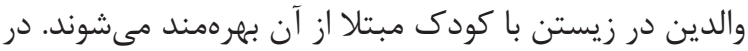

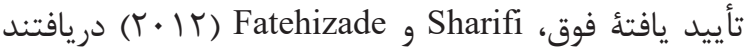

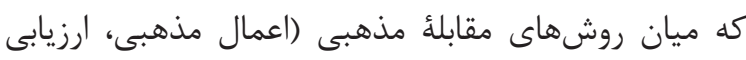

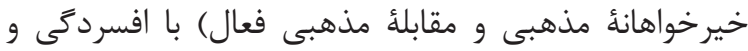

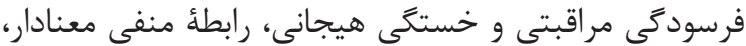

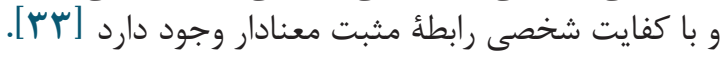

\section{نتيجهل}

والدين كودكان مبتلا به فلج مغزى مى متوانند به كمكى

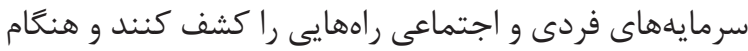

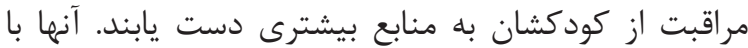

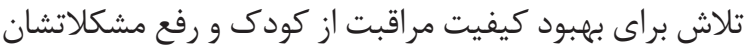

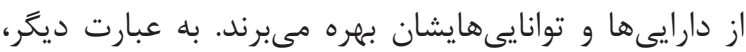

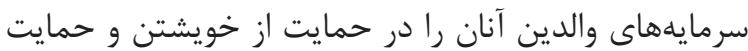

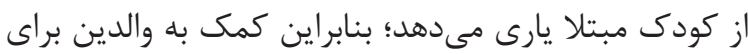

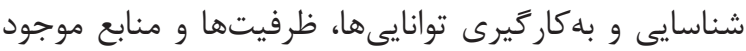

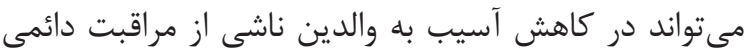

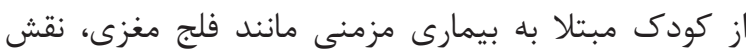
بسز ايى داشته باشد.

مفهوم سرمائُ والدين عاملى يارىرسان است كه در ساير

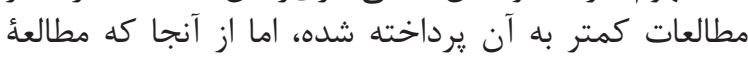

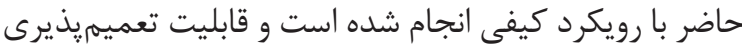

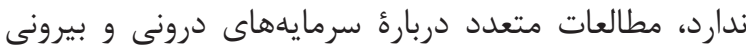

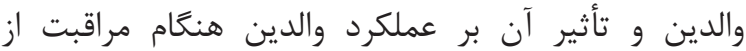

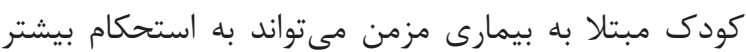

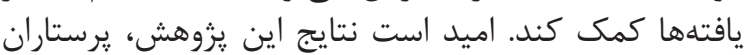

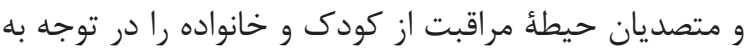

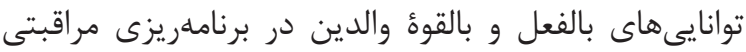

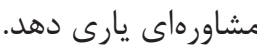

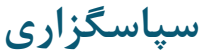

اين مقاله بركرفته از رساله دكترى مصوب دانشگاه

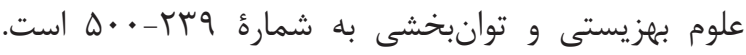

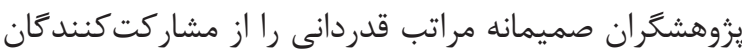
در اين يزوهش اعلام مى كنيند.

$$
\text { تعارض در منافع }
$$

نويسندگان هيجَّنه تعارضى در منافع ندارند.
كه توانايى والدين در حل مشكلات روانشناختى ابتلاى

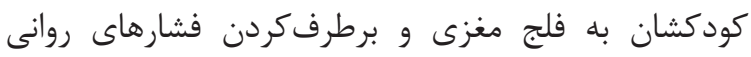

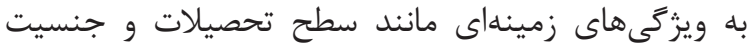

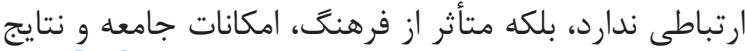

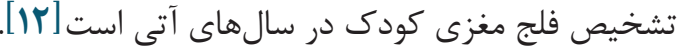

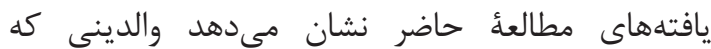

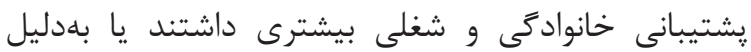

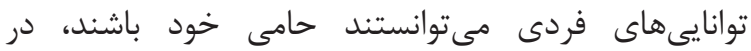

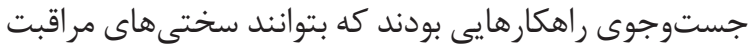

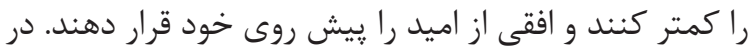

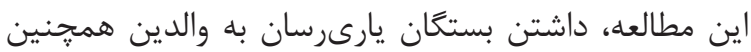

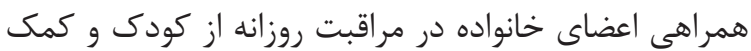

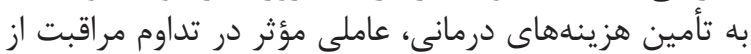

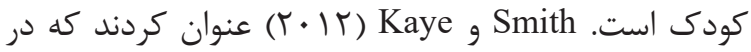

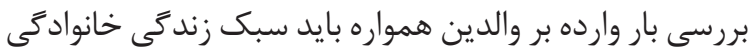

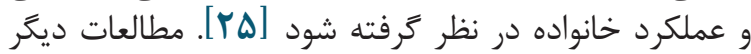

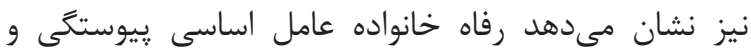

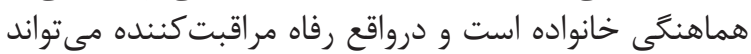

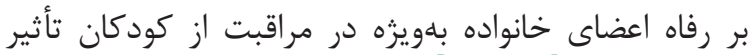

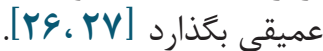
با توجه به مطالعهُ حاضر، حس همكارى ميان والدين

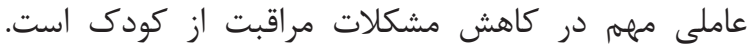
Hwang و Olsson

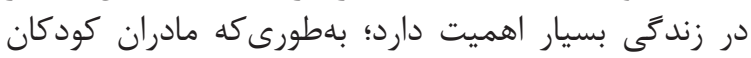

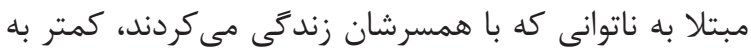

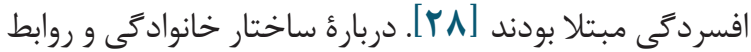

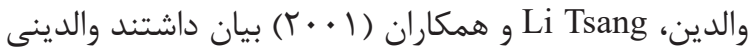

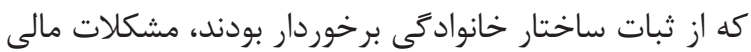

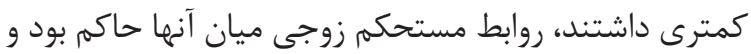

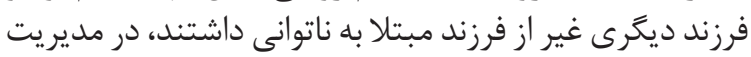

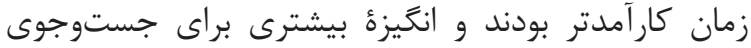

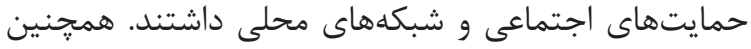

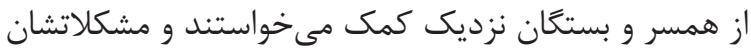

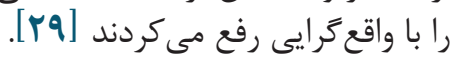
در اين مطالعه اعتقاد والدين مبنى بر ارزش مردي معنوى

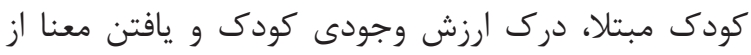

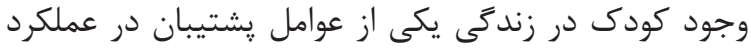

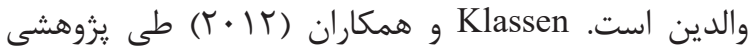

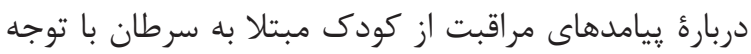

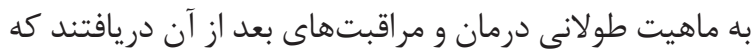

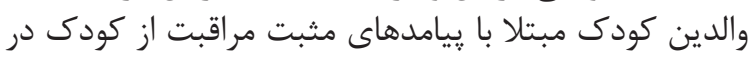

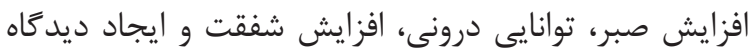

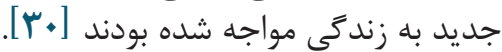

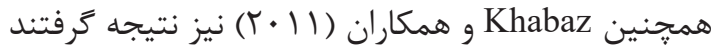
مادرانى كه اعتقاد مذهبى بيشترى دارند، براساس آموزههاى نيز 
צ كوامل مؤثر بر نقش مراقبتى والدين كودكان مبتلا به فلج مغزى

\section{References}

1. Oskoui M, Coutinho F, Dykeman J, Jetté N, Pringsheim T. An Update on the Prevalence of Cerebral Palsy: A Systematic Review and MetaAnalysis. Developmental Medicine and Child Neurology. 2013; 55(6):509-519. https://doi. org/10.1111/dmcn.12080

2. Park E S, Oh W O, Suk M H, Yoon Y M. From Their Own Response: Experiences of Korean Children with Chronic Illness and their Families. Journal of Korean Academy of Child Health Nursing. 2009; 15(4):350-358. https://doi. org/10.4094/jkachn.2009.15.4.350

3. Raina P, O’Donnell M, Rosenbaum P, Brehaut J, Walter S D. Russell D, et al. The Health and Well-Being of Caregivers of Children with Cerebral Palsy. Pediatrics. 2005; 115(6):E626-E636. https://doi.org/10.1542/peds.2004-1689

4. Hockenbery M J, Wilson D, Winkelstein M L. Wong's Essentials Of Pediatric Nursing. $7^{\text {th }}$ Ed. London. St. Louis Mosby; 2005.

5. Lindblad B. M, Holritz Rasmussen B, Sandman PO. A Life Enriching Togetherness-Meanings of Informal Support When Being a Parent of a Child with Disability. Scandinavian Journal of Caring Sciences. 2007; 21(2):238-246. https:// doi.org/10.1111/j.1471-6712.2007.00462.x

6. Park SY, Glidden LM, Shin JY. Structural and Functional Aspects of Social Support for Mothers of Children with and Without Cognitive Delays in Vietnam. Journal of Applied Research in Intellectual Disabilities. 2010; 23(1):38-51. https:// doi.org/10.1111/j.1468-3148.2009.00550.x

7. Reagin AE. Strengthening Health Care For Children: Primary Care and the Medical Home. 2009.

8. Coffey JS. Parenting a Child with Chronic Illness: A Metasynthesis. Pediatric Nursing. 2006; 32(1).

9. The Michigan Developmental Disabilities Council. Family Support Services In Michigan: Family Resources and Services Utilization. Michigan: The Michigan Developmental Disabilities Council; 1992.

10. Jafary Manesh H , Ranjbaran M , Vakilian K , Rezaei K, Zand K, Tajik R. Survey of Levels of Anxiety and Depression in Parents of Children with Chronic Illness. Iranian Journal of Psychiatric Nursing. 2014; 1(4):45-53.

11. Dambi JM, Jelsma J, Mlambo T. Caring for a Child with Cerebral Palsy: The Experience of Zimbabwean Mothers. African Journal of Disability. 2015; 4(1). https://doi.org/10.4102/ajod. v4i1.168
12. Schuengel C, Rentinck ICM, Stolk J, Voorman J M, Loots GMP, Ketelaar M, et al. Parents' Reactions to the Diagnosis of Cerebral Palsy: Associations Between Resolution, Age and Severity of Disability. Child: Care, Health and Development. 2009; 35(5):673-680. https://doi.org/10.1111/ j.1365-2214.2009.00951.x

13. Oyegbile Y O, Brysiewicz P. Exploring Caregiver Burden Experienced By Family Caregivers Of Patients With End-Stage Renal Disease In Nigeria. International Journal Of Africa Nursing Sciences. 2017; 7:136-143. https://doi.org/10.1016/j. ijans.2017.11.005

14. Teymouri F, Alhani F, Kazemnejad A. The Effect of the Family-Centered Empowerment Model on the Quality of Life in Parents of Children with Asthma. Scientific Journal of Hamadan Nursing and Midwifery Faculty. 2014; 22(3):5-14.

15. Hsieh HF, Shannon SE. Three Approaches to Qualitative Content Analysis. Qualitative Health Research. 2005; 15(9):1277-1288. https://doi. org/10.1177/1049732305276687

16. Elo S, Kyngäs H. The Qualitative Content Analysis Process. Journal of Advanced Nursing. 2008; 62(1):107-115. https://doi.org/10.1111/j.13652648.2007.04569.x

17. Polit DF, Beck CT. Essentials of Nursing Research: Methods, Appraisal, and Utilization. Lippincott Williams and Wilkins; 2006.

18. Graneheim UH, Lundman B. Qualitative Content Analysis in Nursing Research: Concepts, Procedures and Measures to Achieve Trustworthiness. Nurse Education Today. 2004; 24(2):105-112.

19. Bakhtiari، M. Social Capital. Available From: www.pajoohe.com. (May Access 2014).

20. Mohammady-Shahbalagy F, Dabbaghi F, Yadavar Nikravesh M. Facilitator and Barriers Factors in Family Caregiving Process of Iranian Frail Elderly: Qualitative Study. Iran Journal of Nursing. 2008; 21(55):55-65.

21. Schwartz C. Parents of Children with Chronic Disabilities: The Gratification of Caregiving. Families in Society. 2003; 84(4):576-584. https:// doi.org/10.1606/1044-3894.143

22. Guillamón N, Nieto R, Pousada M, Redolar D, Muñoz E, Hernández E, et al. Quality of Life and Mental Health Among Parents of Children with Cerebral Palsy: The Influence of Self-Efficacy and Coping Strategies. Journal of Clinical Nursing. 2013; 22(11-12):1579-1590. https://doi. org/10.1111/jocn.12124

23. Bastani F, Ghasemi E, Negarandeh R, Haghan H. 
General Self-Efficacy Among Family's Female Caregiver of Elderly with Alzheimer's Disease. Journal of Hayat. 2012; 18(2):27-37.

24. Nikfarid L, Eezadi H, Shakoori M. Coping Behaviors of Mothers of Chronically Ill Children. Iran Journal of Nursing (2008-5923). 2012; 24(74).

25. Smith BA, Kaye DL. Treating Parents of Children with Chronic Health Conditions: The Role of the General Psychiatrist. Focus. 2012; 10(3):255265. https://doi.org/10.1176/appi.focus.10.3.255

26. Pilowsky D J, Wickramaratne P, Yoko N, Weissman MM. Family Discord, Parental Depression, and Psychopathology in Offspring: 20-Year Follow-Up. Journal of the American Academy of Child and Adolescent Psychiatry. 2006; 45(4):452-460. https://doi.org/10.1097/01. $\underline{\text { chi. } 0000198592.23078 .8 \mathrm{~d}}$

27. Meadows SO, Mclanahan SS, Brooks-Gunn J. Parental Depression and Anxiety and Early Childhood Behavior Problems Across Family Types. Journal of Marriage and Family. 2007; 69(5):1162-1177. https://doi.org/10.1111/j.17413737.2007.00439.x

28. Olsson MB, Hwang CP. Depression in Mothers and Fathers of Children with Intellectual Disability. Journal of Intellectual Disability Research. 2001; 45(6):535-543. https://doi.org/10.1046/ j.1365-2788.2001.00372.x

29. Li-Tsang CW, Yau MK, Yuen HK. Success in
Parenting Children with Developmental Disabilities: Some Characteristics, Attitudes and Adaptive Coping Skills. The British Journal of Development Disabilities. 2001; 47(93):61-71. https:// doi.org/10.1179/096979501799155594

30. Klassen A F, Gulati S, Granek L, Rosenberg-Yunger Z R S, Watt L, Sung L, et al. Understanding The Health Impact of Caregiving: A Qualitative Study of Immigrant Parents and Single Parents of Children with Cancer. Quality of Life Research. 2012; 21(9):1595-1605. https:// doi.org/10.1007/s11136-011-0072-8

31. Khabaz M, Rezapour MirSalih Y, Abdi K, Safi M E. A Comparative Study Between the Role of Religious Orientations and Personality Dimensions in the Prediction of Coping Strategies in Mothers of Children with and Without Intellectual Disability. Journal of Rehabilitation. 20111; 12(2):41-47.

32. Mir G, Tovey P. Asian Carers' Experiences of Medical and Social Care: The Case of Cerebral Palsy. British Journal of Social Work. 2003; 33(4):465-479. https://doi.org/10.1093/ bjsw/33.4.465

33. Sharifi M, Fatehizade M. Correlation Between Religious Coping and Caregiver Depression Burnout in Family Caregivers. Modern Care , Scientific Quarterly of Birjand Nursing and Midwifery Faculty. 2012; 9(4):327-335. 